\title{
The Effect of Tumor Localization and Clinicopathological Factors on Intravesical Recurrence and Survival in Primary Upper Urinary Tract Urothelial Tumors
}

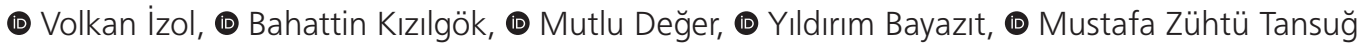 \\ Çukurova University Faculty of Medicine, Department of Urology, Adana, Turkey
}

\begin{abstract} excision due to primary upper urinary system urothelial tumor (UUST) in our clinic. Recurrent-free survival was significantly worse in ureteral tumors (Hazard ratio:3, $p=0.04$ ). Keywords: Urothelial carcinoma, intravesical recurrence, cancer, ureters

\section{Introduction}

Urothelial tumors of the upper urinary tract (UUST) are extremely rare tumors, accounting for approximately 5-10\% of all urothelial tumors (1). Pyelocaliceal tumors are more than twice as likely as isolated ureteral tumors, and $17 \%$ of UUSTs have simultaneous bladder cancer. After treatment, bladder recurrence is observed in $22-47 \%$ and contralateral UUST recurrence in $2-6 \%$ (1). Preoperative prognostic markers in UUST include tumor diameter, grade, localization, multifocality, hydronephrosis, and gender. Postoperative prognostic markers in UUST are stage, grade, lymph node involvement and histological variant of the tumor $(1,2)$. The disease is approximately $60 \%$ invasive at the time of diagnosis and the gold standard treatment method is radical nephroureterectomy (RNU) and lymph node dissection
\end{abstract}

Objective: We aimed to investigate the factors affecting intravesical recurrence and survival in patients undergoing radical nephroureterectomy and bladder cuff

Materials and Methods: The data of 52 patients who were operated for primary UUST between 2008 and 2018 were retrospectively evaluated. All patients underwent preoperative computed tomography and magnetic resonance urography. Tumor localizations were grouped according to the ureteropelvic compound. During the follow-up period after radical surgery, the patients underwent physical examination, routine blood tests and radiological evaluation. The patients were followed up quarterly in the first two years, every six months for the next two years and then yearly with cystoscopy.

Results: Thirteen female and 39 male patients with an average age of $60.5 \pm 10.35$ years were included in the study. Mean follow-up time was $66.8 \pm 38.2$ months Thirty (58\%) patients had renal tumors, $13(25 \%)$ patients had ureteral tumors and $9(17 \%)$ patients had multifocal tumors. Intravesical recurrence was detected in $9(69 \%)$ patients with ureteral tumor ( $p=0.047)$. Ten-year overall survival of patients with ureteral tumors was $50 \%$ (35.4\% side effect) (Log rank test $=0.012)$.

Conclusion: The ureteral tumor group was significantly worse in terms of postoperative intravesical recurrence and overall survival and recurrence-free survival.

involving bladder cuff excision. Local advanced disease and lymph node metastasis are detected in approximately $20-40 \%$ of patients at the time of diagnosis. Although RNU and bladder cuff excision are performed, 5-year disease-specific mortality rates are $15 \%$ in pT2N0 disease, $45 \%$ in pT3N0 disease and $88 \%$ in pT4N0 disease (2).

A new meta-analysis have identified significant determinants of postoperative intravesical recurrence (PIVR) after RNU (3). Patient-specific factors are male gender, previous bladder cancer, smoking, and preoperative chronic renal disease; tumorspecific factors are preoperative positive urine cytology, tumor localization multifocality, pathologic stage, and necrosis; and treatment-specific factors are laparoscopic approach, surgical removal of the bladder cuff by extravesical route and positive surgical boundary (3). 
In this study, we investigated age, genderw, presence of preoperative hydronephrosis, smoking, tumor localization, and the effect of surgical technique and pathological stage on PIVR and survival in patients with primary UUST.

\section{Materials and Methods}

Our study included 52 patients who underwent RNU due to primary UUST between 2008 and 2018. The data from the urological cancers database, which were being recorded prospectively in our clinic, were retrospectively evaluated for this study. Computed tomography urography and magnetic resonance urography were used for preoperative imaging of patients. Tumors were divided into three groups according to their localization, according to ureteropelvic junction (UPJ):

I. Tumors above UPJ: Renal tumors.

II. Tumors below UPJ: Ureteral tumors.

III. More than one tumor in both kidneys and ureters, or single tumor that takes up space both below and above UPJ: Multifocal tumors, i.e. tumors placing in kidney and ureter.

All patients' urine was evaluated cytologically during preoperative period. Thirty-three patients underwent ureterorenoscopy (URS) before radical surgery. Sixteen of these underwent biopsy and mass was seen in the collector system in 17 patients and they did not undergo biopsy.

RNU was performed with standard open (4) and laparoscopic methods. In laparoscopic RNU, two different methods were applied for the distal ureter. In 12 of the patients, after the nephrectomy was completed laparoscopically, the bladder cuff excision was performed by the open method. In 20 of the 5 patients, intraoperative distal ureteral and intravesical chemotherapy techniques were applied during laparoscopic RNU and for this, the operation was started in lithotomy position. A ureteral catheter was inserted into the ureter so that the tip remained distal to the tumor, and then it was fixed to urethral catheter. Then, the position was changed to laparoscopic RNU. In the early stage of the operation, after the ureter was found and clamped in the distal part of the tumor level and after the patient's urethral catheter was also clamped; Mitomycin $(20 \mathrm{mg})$ or Epirubicin $(50 \mathrm{mg})$ diluted in $50 \mathrm{~mL}$ distilled water was given from the ureteral catheter, while in a small number of patients in whom these were not found, distilled water was slowly administered. When irrigation was completed, the ureteral catheter was removed and the urethral catheter remained closed. Thus, the chemotherapeutic agent was allowed to wash the distal part of ureter and wait in the bladder until the cuff excision. Just prior to the cuff excision, the bladder was emptied and extensively irrigated. Following this, the cuff excision was performed by incising detrusor fibers all the way to the bladder mucosa circumferentially and attaching clips to the bladder mucosa, including the ureteral orifice and the surrounding area.

Paraortic and iliac lymph node dissections were performed in both open and laparoscopic methods and the operation was completed.

There were two patients who underwent radical nephrectomy because urothelial carcinoma (UC) was not considered at the forefront in preoperative examinations. In the histopathological examination of these patients, UC was detected and ureteral stump and bladder cuff excisions were applied.

\section{Statistical Analyses}

Statistical analyses were performed in SPSS V23.0 program and $\mathrm{p}<0.05$ was considered statistically significant. The chisquare test for categorical variables, Kaplan-Meier test for survival analysis, and single and multivariate Cox regression analyses were used. Ethics committee approval was received for this study from the Ethics Committee of Çukurova University (approval number: December 2018,7).

\section{Results}

In our study, 13 of 52 (25\%) patients who underwent surgery for UUST were female and 39 (75\%) were men and they had an average age of $60.5 \pm 10.35(38-86)$ years. Forty $(76.9 \%)$ patients had cigarette use, while $12(23.1 \%)$ patients did not. At the time of diagnosis, 31 (59.6\%) patients had hematuria, while $21(40.4 \%)$ patients had no hematuria. The cytology of 17 (32.7\%) patients was positive for malignancy and the cytology of $35(67.3 \%)$ patients was negative. In preoperative imaging, 25 (48.1\%) patients had hydronephrosis, while 27 (51.9\%) patients had no hydronephrosis. The mean tumor diameter of the patients was $4.58 \pm 2.18(1-10) \mathrm{cm}$. Renal tumor was found in $30(57.7 \%)$ patients, ureteral tumor was found in 13 (25\%) patients and both renal and ureteral tumors (multifocal localization) were found in $9(17.3 \%)$ patients.

Thirty-three (63\%) patients underwent URS before radical surgery. Sixteen (30\%) patients underwent a biopsy, while a mass was found within the collector system in 17 (32\%) patients and they did not undergo biopsy. Histopathological examinations of biopsies performed during URS were reported as suspicious UC in 4 patients, UC with unspecified grade in 2 patients, low grade UC in 8 patients and high grade UC in 2 patients.

Twenty (38.5\%) patients underwent open RNU and 32 (51.5\%) patients underwent laparoscopic RNU and lymph node dissection. In histopathological evaluation, low grade UC was found in 12 (23.1\%) patients and high grade UC was found in $40(76.9 \%)$ patients. There was no sign of carcinoma in situ in specimens.

Histopathology of 16 out of 17 patients with positive preoperative urinary cytology and 24 out of 35 patients with negative preoperative urinary cytology was reported as high grade UC ( $p>0.05)$. The histopathology of 20 out of 25 patients with preoperative hydronephrosis and 20 out of 27 patients without hydronephrosis was reported as high grade UC ( $p>0.05)$. Histopathological gradings according to tumor localization are given in Table 1. Nineteen of the patients included in our study were older than 66 years and all were reported as having high grade UC histopathology. Of the 33 patients under the age of 66 years, 12 had low grade UC histopathology and 21 had high grade UC histopathology (Table 2$)(p=0.02)$.

In postoperative follow-up, PIVR was found in 22 (42.3\%) patients. PIVR was found in 7 (41\%) of 17 patients with positive preoperative urinary cytology and in 15 (42\%) of 35 patients 
with negative preoperative urinary cytology $(p>0.05)$. PIVR was observed in $15(60 \%)$ of 25 patients with preoperative hydronephrosis, while PIVR was observed in 12 (44\%) of 27 patients without preoperative hydronephrosis $(p>0.05)$. PIVR was not found in $17(42 \%)$ of 40 patients who smoked and PIVR was found in 5 (41\%) of 12 patients who did not smoke $(p>0.05)$. PIVR was found in $17(51.5 \%)$ of 33 patients who underwent URS, while PIVR was found in 5 (26.3\%) of 19 patients who did not undergo URS $(p=0.07)$. The frequency of PIVR was similar in patients who underwent laparoscopic or open surgery $(40.6 \%$ and $45 \%$, respectively) ( $p>0.05)$. PIVR ratios according to tumor localization are given in Table 3.

The mean duration of follow-up was $66.8 \pm 38.2$ months in postoperative period and 2 patients died due to cancer-related causes and 4 patients died due to non-disease causes. Ten patients were not included in the survival analyses because they could not be reached.

Five-year overall survival (OS) according to tumor localization was $95 \%$ [4.1\% side effect (SE)] in renal tumors, $100 \%$ in ureteral tumors, $83 \%$ (15\% SE) in tumors with multifocal localization. Ten-year OS was $76 \%$ (17.4\% SE) in renal tumor, $50 \%$ (35.4\% SE) in ureteral tumors, $27 \%$ (23.2\% SE) in tumors with multifocal localization $[95 \%$ confidence interval $(\mathrm{Cl})$, 61-92], $(p=0.012)$, (Figure 1).

Five-year recurrence-free survival (RFS) according to tumor localization was $63 \%$ ( $8.9 \% \mathrm{SE})$ in renal tumors and $28 \%$ (13.1\% SE) in ureteral tumors $(95 \% \mathrm{Cl}, 12-23),(p=0.082)$, (Figure 2).
In Tables 4 and 5, the results of the single and multivariate Cox regression analyses to predict OS and RFS, respectively are given. There was a significant difference between groups in terms of OS in favor of tumors with multifocal localization in single variable regression analysis $(p<0.05)$, (Table 4). Although ureteral tumors had lower RFS, there was no statistically significant difference $[p=0.05$, hazard ratio (HR)]. The parameters involved in multivariate regression analysis were tumor localization, grade of tumor, pathological stage of tumor, lymph node involvement, preoperative URS and intraoperative Mitomycin/Epirubicin application. There was a significant difference between groups in terms of RFS in favor of ureteral tumors in multivariate regression analysis ( $p=0.04, \mathrm{HR}: 3)$. Also, N1 stage lymph node involvement was found to be statistically significantly associated with lower RFS in multivariate regression analysis ( $p=0.01, \mathrm{HR}: 32)$.

\section{Discussion}

UUST constitutes approximately $5-10 \%$ of all urothelial tumors

\begin{tabular}{|c|c|c|c|}
\hline \multirow[t]{2}{*}{ Age (year) } & \multicolumn{2}{|c|}{$\begin{array}{l}\text { Histopathological } \\
\text { grade of tumor }\end{array}$} & \multirow[t]{2}{*}{ p } \\
\hline & $\begin{array}{l}\text { Low } \\
n=12,23 \%\end{array}$ & $\begin{array}{l}\text { High } \\
\mathrm{n}=40,77 \%\end{array}$ & \\
\hline$\leq 65$ & $12(100)$ & $21(53)$ & \multirow[t]{2}{*}{0.02} \\
\hline$\geq 65$ & $0(0)$ & $19(47)$ & \\
\hline
\end{tabular}

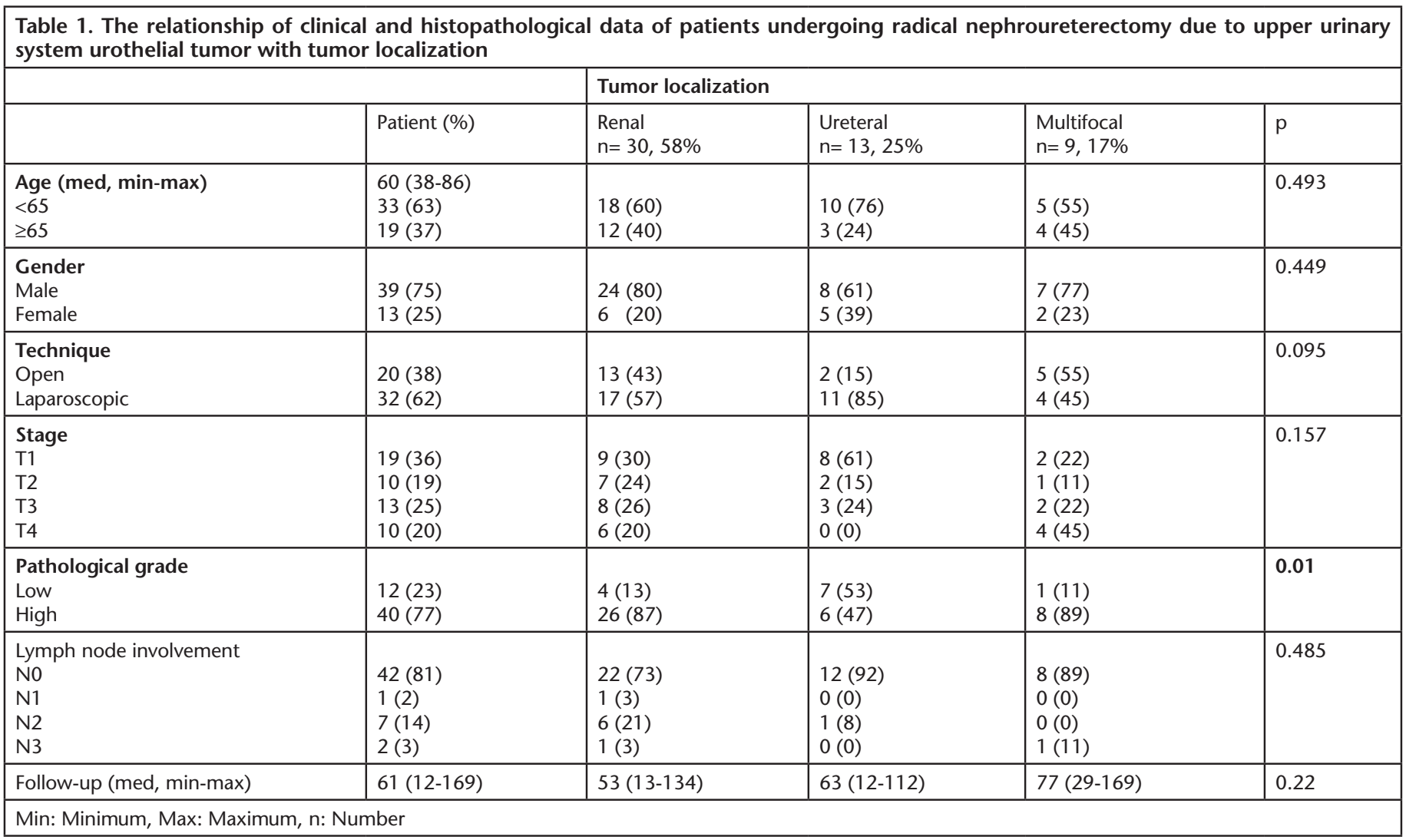




\begin{tabular}{|c|c|c|c|c|}
\hline \multirow{3}{*}{$\begin{array}{l}\text { Tumor localization } \\
\text { Renal } \\
\text { Ureteral } \\
\text { Multifocal }\end{array}$} & \multirow{3}{*}{$\begin{array}{l}\text { Patient (\%) } \\
\\
30(58) \\
13(25) \\
9(17)\end{array}$} & \multicolumn{3}{|c|}{ Intravesical recurrence } \\
\hline & & Yes $(n=22,42 \%)$ & No $(n=30,58 \%)$ & $\mathrm{p}$ \\
\hline & & $\begin{array}{l}11(50) \\
9(41) \\
2(9)\end{array}$ & $\begin{array}{l}19(63) \\
4(13) \\
7(24)\end{array}$ & 0.047 \\
\hline $\begin{array}{l}\text { Diagnostic ureterorenoscopy } \\
\text { Done } \\
\text { Not done }\end{array}$ & $\begin{array}{l}33(63) \\
19(37)\end{array}$ & $\begin{array}{l}17(77) \\
5(23)\end{array}$ & $\begin{array}{l}16(53) \\
14(47)\end{array}$ & 0.077 \\
\hline $\begin{array}{l}\text { Technique } \\
\text { Open } \\
\text { Laparoscopic }\end{array}$ & $\begin{array}{l}20(38) \\
32(62)\end{array}$ & $\begin{array}{l}9(41) \\
13(59)\end{array}$ & $\begin{array}{l}11(37) \\
19(63)\end{array}$ & 0.756 \\
\hline $\begin{array}{l}\text { Epirubicin } \\
\text { Done } \\
\text { Not Done }\end{array}$ & $\begin{array}{l}20(38) \\
32(62)\end{array}$ & $\begin{array}{l}9(41) \\
13(59)\end{array}$ & $\begin{array}{l}11(37) \\
19(63)\end{array}$ & 0.756 \\
\hline
\end{tabular}

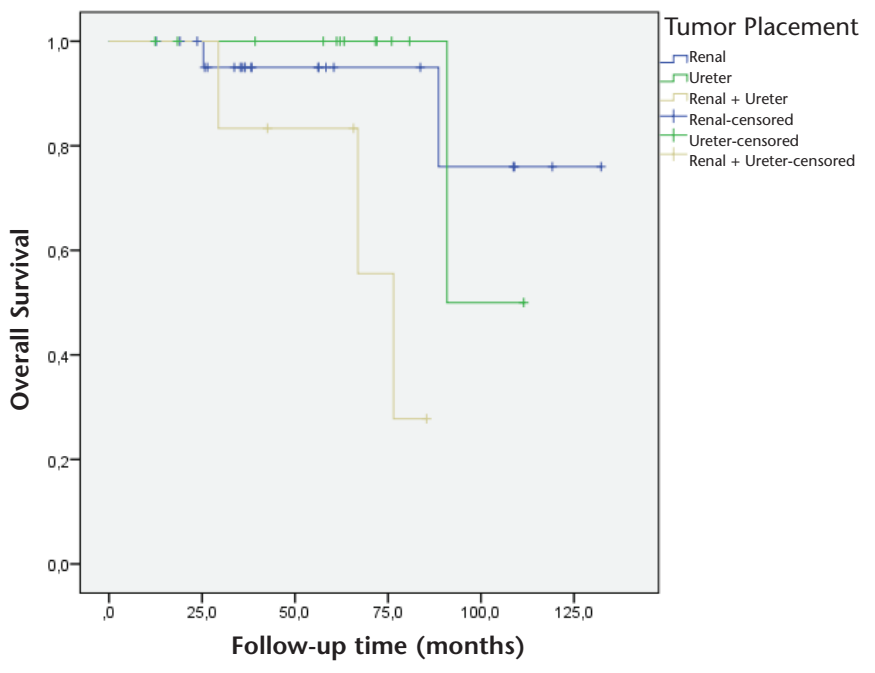

Figure 1. Effect of tumor localization on overall survival. Log- rank test $=0.012$

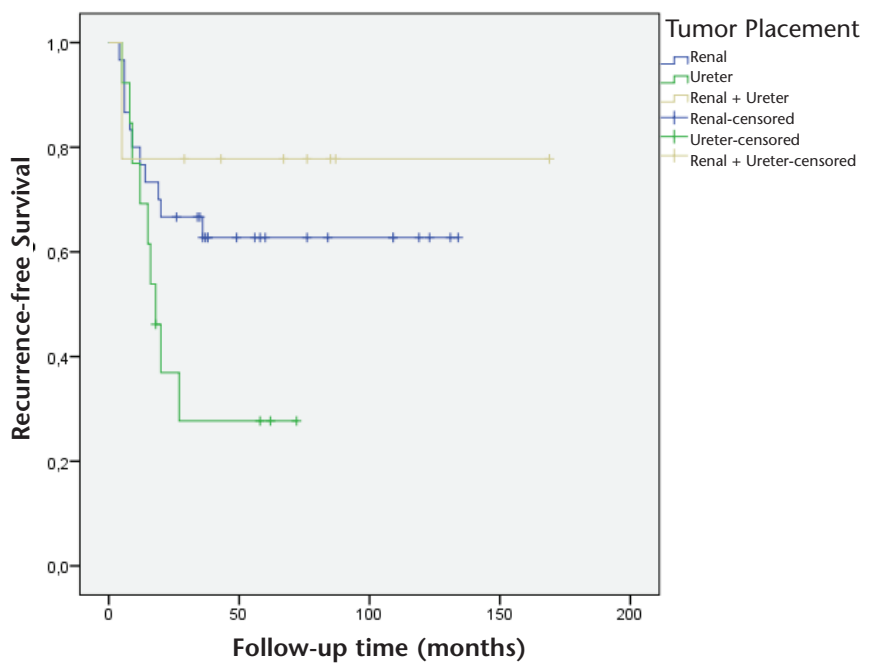

Figure 2. Effect of tumor localization on recurrence-free overall survival. Logrank test $=0.082$

(1). Preoperative prognostic markers include tumor diameter, grade, tumor localization, multifocality, hydronephrosis, and gender. Postoperative prognostic markers include stage of the tumor, its grade, histological variant and lymph node involvement $(1,2,3,4,5,6)$. Different approaches can be applied to patients divided into low and high risk groups according to preoperative and postoperative markers. Patients in the high risk group are treated with RNU, which is the gold standard treatment method, while patients in the low risk group may be treated with Nephron-sparing surgery methods.

PIVR is an important problem that should not be overlooked in patients undergoing surgical treatment due to UUST. Therefore, identifying high-risk patients with respect to PIVR can contribute to the quality of monitoring and the survival of patients who develop PIVR by ensuring that follow-up protocols are regulated accordingly. Therefore, the number of various studies examining different risk factors in the literature increases over time.

In the literature, an increase in postoperative mortality and PIVR risk has been reported in patients using tobacco products, especially cigarettes (7). In our study, there was no significant increase in postoperative bladder recurrence in smoking patients $(p>0.05)$. Although there is no threshold value to predict the effect of cigarette consumption on PIVR, it has been thought that this may be related to the amount of cigarette consumption.

There are studies in the literature showing that preoperative hydronephrosis increases the risk of PIVR by indirect means (3). No significant relationship between preoperative hydronephrosis and histopathological grade and IVR was found in our study $(p>0.05)$. The relationship of preoperative hydronephrosis with PIVR was shown in large series and meta-analyses and we thought that we encountered a different result from the literature due to the small number of patients in our study.

Another risk factor for PIVR is the surgical approach. In a meta-analysis of clinicopathological factors effecting PIVR, laparoscopic approach has been reported to increase the risk of PIVR compared to open surgery $(2,3,4,5,6,7,8)$. However, there was no significant relationship between the surgical techniques and PIVR in our study $(p>0.05)$ (Table 3$)$. There was no difference in terms of PIVR between the two different methods used for bladder cuff excision in our clinic, suggesting that both techniques were oncologically safe. 


\begin{tabular}{|c|c|c|c|c|c|c|}
\hline \multirow[b]{2}{*}{ Parameter } & \multicolumn{3}{|c|}{ Univariate analysis } & \multicolumn{3}{|c|}{ Multivariate analysis } \\
\hline & HR & $95 \% \mathrm{Cl}$ & $p$ & HR & $95 \% \mathrm{Cl}$ & $p$ \\
\hline $\begin{array}{l}\text { Tumor localization } \\
\text { Renal } \\
\text { Ureteral } \\
\text { Multifocal }\end{array}$ & $\begin{array}{l}1 \\
0.9 \\
13.6\end{array}$ & $\begin{array}{l}\text { Ref } \\
0.8-10 \\
1.1-158\end{array}$ & \begin{tabular}{|l} 
\\
0.98 \\
0.03
\end{tabular} & $\begin{array}{l}1 \\
1.8 \\
2.23\end{array}$ & $\begin{array}{l}\text { Ref } \\
0-86 \\
0-349\end{array}$ & $\begin{array}{l}- \\
0.88 \\
0.87\end{array}$ \\
\hline Tumor grade & 30 & $0.6-167$ & 0.4 & 1.4 & $0-108$ & 0.98 \\
\hline $\begin{array}{l}\text { Tumor Stage } \\
\text { T1 } \\
\text { T2 } \\
\text { T3 } \\
\text { T4 }\end{array}$ & $\begin{array}{l}1 \\
0.8 \\
21 \\
1060\end{array}$ & $\begin{array}{l}\text { Ref } \\
0-3253 \\
0-3267 \\
0-46760\end{array}$ & \begin{tabular}{|l} 
\\
0.98 \\
0.61 \\
0.36 \\
\end{tabular} & $\begin{array}{l}1 \\
1.01 \\
2.44 \\
339 \\
\end{array}$ & $\begin{array}{l}\text { Ref } \\
0-5.81 \\
0-145 \\
0-1917 \\
\end{array}$ & $\begin{array}{l}- \\
0.99 \\
0.97 \\
0.81 \\
\end{array}$ \\
\hline $\begin{array}{l}\text { Lymph node involvement } \\
\text { N0 } \\
\text { N1 } \\
\text { N2 } \\
\text { N3 }\end{array}$ & $\begin{array}{l}1 \\
3.4 \\
0 \\
11.7 \\
\end{array}$ & $\begin{array}{l}\text { Ref } \\
0.3-35 \\
0 \\
0.9-139\end{array}$ & \begin{tabular}{|l}
- \\
0.3 \\
0.9 \\
0.05 \\
\end{tabular} & $\begin{array}{l}1 \\
7.5 \\
0.1 \\
8.8 \\
\end{array}$ & $\begin{array}{l}\text { Ref } \\
0-5423 \\
0-315 \\
0-3060 \\
\end{array}$ & $\begin{array}{l}- \\
0.65 \\
0.67 \\
0.59 \\
\end{array}$ \\
\hline Ureterorenoscopy & 0.7 & $0.1-4$ & 0.7 & 1.04 & $0.9-119$ & 0.98 \\
\hline Epirubicin/Mitomycin & 0.8 & $0.1-4.5$ & 0.8 & 0.8 & $0.1-129$ & 0.95 \\
\hline
\end{tabular}

Table 5. Single and multivariate Cox regression analyses showing the effects of prognostic markers on recurrence-free survival in patients undergoing radical nephroureterectomy

\begin{tabular}{|c|c|c|c|c|c|c|}
\hline \multirow[b]{2}{*}{ Parameter } & \multicolumn{3}{|c|}{ Univariate analysis } & \multicolumn{3}{|c|}{ Multivariate analysis } \\
\hline & HR & $95 \% \mathrm{Cl}$ & $p$ & HR & $95 \% \mathrm{CI}$ & $p$ \\
\hline $\begin{array}{l}\text { Tumor localization } \\
\text { Renal } \\
\text { Ureteral } \\
\text { Multifocal }\end{array}$ & $\begin{array}{l}1 \\
2.2 \\
0.6 \\
\end{array}$ & $\begin{array}{l}\text { Ref } \\
0.9-5.4 \\
0.1-2.7 \\
\end{array}$ & $\begin{array}{l}- \\
0.07 \\
0.5 \\
\end{array}$ & \begin{tabular}{|l}
1 \\
3 \\
0.7 \\
\end{tabular} & \begin{tabular}{|l|} 
Ref \\
$1.01-8.9$ \\
$0.1-5$ \\
\end{tabular} & \begin{tabular}{|l}
- \\
0.04 \\
0.7 \\
\end{tabular} \\
\hline Tumor grade & 0.8 & $0.3-2.1$ & 0.6 & 1.7 & $0.4-7$ & 0.4 \\
\hline $\begin{array}{l}\text { Tumor Stage } \\
\text { T1 } \\
\text { T2 } \\
\text { T3 } \\
\text { T4 }\end{array}$ & $\begin{array}{l}1 \\
1.5 \\
0.4 \\
0.5\end{array}$ & $\begin{array}{l}\text { Ref } \\
0.5-4.1 \\
0.1-1.4 \\
0.1-2.06\end{array}$ & $\begin{array}{l}- \\
0.38 \\
0.17 \\
0.38 \\
\end{array}$ & \begin{tabular}{|l|}
1 \\
1.5 \\
0.2 \\
0.6 \\
\end{tabular} & $\begin{array}{l}\text { Ref } \\
0.39-5.7 \\
0.03-1.6 \\
0.07-6.7\end{array}$ & $\begin{array}{l}- \\
0.54 \\
0.15 \\
0.74 \\
\end{array}$ \\
\hline $\begin{array}{l}\text { Lymph node involvement } \\
\text { N0 } \\
\text { N1 } \\
\text { N2 } \\
\text { N3 }\end{array}$ & $\begin{array}{l}1 \\
7.7 \\
0.5 \\
1.2 \\
\end{array}$ & $\begin{array}{l}\text { Ref } \\
0.9-64 \\
0.1-2.4 \\
0.1-9.4 \\
\end{array}$ & $\begin{array}{l}- \\
0.05 \\
0.43 \\
0.82 \\
\end{array}$ & \begin{tabular}{|l|}
1 \\
32 \\
0.9 \\
2.1 \\
\end{tabular} & \begin{tabular}{|l} 
Ref \\
$2.08-505$ \\
$0.1-5.9$ \\
$0.1-33$ \\
\end{tabular} & $\begin{array}{l}- \\
0.01 \\
0.93 \\
0.59\end{array}$ \\
\hline Ureterorenoscopy & 0.4 & $0.1-1.1$ & 0.1 & 0.7 & $0.2-2.3$ & 0.59 \\
\hline Epirubicin/Mitomycin & 1.08 & $0.4-2.5$ & 0.8 & 0.93 & $0.3-2.8$ & 0.9 \\
\hline
\end{tabular}

There are studies showing that gender is related to PIVR in UUST. Tanaka et al. (9) reported an increased risk of PIVR in men in the study involving 474 patients. However, Seisen et al. (3) found no significant relationship between gender and PIVR in their meta-analysis including 5376 patients including that study. In our study, there was no correlation between gender and PIVR in line with this meta-analysis ( $p>0.05)$.

It has been reported that patients' cancer-specific survival may decrease as age increases $(10,11,12)$. There is no clear information in the literature regarding one-to-one relationship between tumor grade and PIVR. In our study, tumor grades were higher in patients in the middle or above age group $(\geq 66$ years) (13), $(p<0.05)$. Cancer-specific survival rate was not measured in our study, because mortality due to cancer was limited to 2 patients in our patient series.

In our study, when the relationship between tumor localization and postoperative tumor grade was examined, it was determined that the postoperative tumor degree in renal tumors was higher than ureteral tumors $(p<0.05)$ (Table 1$)$. In the literature, there was no significant difference in between renal and ureteral tumors in terms of postoperative histopathological grades in large series $(14,15)$.

Baboudjian et al. (14) compared 1041 patients with pre-RNU URS with 2909 patients without URS in terms of PIVR in their 
review in 2019 and found that recurrence was higher in the URS group $(p<0.05)$. Although there was no significant difference in terms of PIVR between "URS" and "No URS" groups in our study, it was thought that if the number of patients was higher, the data could be compatible with the literature $(p=0.07)$ (Table 3$)(16)$.

Pyelocaliceal tumors are more than twice as common as isolated ureteral tumors $(1,15)$. The prognosis of ureteral or multifocal tumors has been shown to be worse than that of renal pelvis tumors, when all UUSTs are taken into account $(14,15,17,18)$. Yafi et al. (12) showed in their study performed in 637 patients who underwent RNU and bladder cuff excision due to UUST, that 5-year survival rate was lower and cancerspecific mortality rate and recurrence were higher in patients with ureteral tumor compared with patients with renal tumor. Our study also showed that the overall survival of patients with ureteral tumor was lower than patients with renal tumor (95\% $\mathrm{Cl}, 61-92)(p=0.012)$ (Figure 1).

Seisen T et al. (3) screened 12 publications evaluating the effect of tumor localization on PIVR in their review. It was shown that ureteral tumors were found to be associated with higher PIVR rates $(p<0.01)$ in a total of 6017 patients with UUST, including 2229 (37\%) patients with ureteral tumor and 3788 (63\%) patients with renal tumor. In our study, high rates of PIVR were found in ureteral tumors in line with the literature (HR:3, $\mathrm{p}<0.05)$ (Table 5) $(14,15,18)$.

\section{Study Limitations}

Although the data evaluated in this study were obtained from the uro-oncology database, which was being held prospectively in our clinic, retrospective examination of these data for our study was a significant limitation of our study. The low number of patients compared to the broad series in the literature was another weakness. The reasons for this weakness were that the study was single-centered and actually involved only patients with primary diagnosis, which was also an important feature of the study. There were no patients treated with minimally invasive ablative treatment in our series. Therefore, it was not included in our study.

\section{Conclusion}

In our study, it was determined that among the primary UUSTs, ureteral and multifocal tumors had a higher risk for PIVR than renal tumors and 5-year OS rate was lower in ureteral tumors compared with renal tumors

The risk groups of the patients should be determined according to the tumor localization at the diagnosis stage in primary UUST. In particular, it may be useful to make adjustments in the duration and frequency of follow-up of patients with ureteral tumors, taking into account the excess risk of PIVR and the low risk of OS.

We believe that prospective studies with larger number of patients are needed to help tailor post-treatment follow-up of patients with UUST to patient risk groups.

\section{Acknowledgements}

Publication: The results of the study were not published in full or in part in form of abstracts.
Contribution: There is not any contributors who may not be listed as authors.

Conflict of Interest: No conflict of interest was declared by the authors.

Financial Disclosure: The authors declared that this study received no financial support.

\section{Ethics}

Ethics Committee Approval: Ethics committee approval was received for this study from the Ethics Committee of Çukurova University (approval number: December 2018,7).

Informed Consent: Retrospective study.

Peer-review: Externally peer-reviewed.

\section{Authorship Contributions}

Surgical and Medical Practice: V.İ., Y.B., Z.T., Concept: V.İ., B.K., Design: V.I., B.K., Y.B., Data Collection or Pocessing: M.D., B.K., Analysis or Interpretation: V.I., Y.B., Z.T., Literature Search: B.K., M.D., Writing: V.I.., B.K., Y.B.

\section{References}

1. Siegel RL1, Miller KD, Jemal A., et al. Cancerstatistics, 2015. CA Cancer J Clin 2015;65:5-29.

2. Behfar Ehdaie, Shahrokh F. Shariat, Caroline, Savage, Jonathan Coleman, Guido Dalbagni. Postoperative Nomogram for Disease Recurrenceand Cancer-Specific Death for Upper Tract Urothelial Carcinoma: Comparisonto American Joint Committee on Cancer Staging Classification. Urology Journal 2014;11:2.

3. Seisen T, Granger B, Colin P, et al. A Systematic Reviewand Metaanalysis of Clinicopathologic Factors Linked to Intravesical Recurrence After Radical Nephroureterectomy to Treat Upper Tract Urothelial Carcinoma. EurUrol 2015;67:1122-1133.

4. Sagalowsky A, Jarrett T. Üst Üriner Yol ve ÜreterinÜrotelyal Tümörleri, Campbell-WalshUrology, Tenth Edition 2014;1530.

5. Bayazıt Y, İol V, Laparoskopik radikal nefroüreterektomi sırasında hücre ekimi riskini azaltmada distalüreter ve mesane irrigasyon tekniği.10. Üroonkoloji Kongresi Bildiri Özetleri Kitabı, P-18, 131, Antalya, 26-30 Ekim 2011.

6. Margulis V, Shariat SF, Matin SF, et al. Outcomes of radical nephroureterectomy: a series from the Upper Tract Urothelial Carcinoma Collaboration. Cancer 2009;115:1224-1233.

7. Simsir A, Sarsik B, Cureklibatur I, et al. Prognostic factors for upper urinary tracturo the lial carcinomas: stage, grade, andsmokingstatus. IntUrolNephrol 2011;43:1039.

8. Zou L, Zhang L, Zhang H, Jiang H, Ding Q. Comparison of postoperative intravesical recurrence and oncological outcomes after open versus laparoscopic nephroureterectomy for upper urinary tracturo the lial carcinoma. World J Urol 2014;32:565-570.

9. Tanaka N, Kikuchi E, Kanao K, et al. Thepredictivevalue of positive urinecytology for outcomes following radical nephroureterectomy in patients with primary upper tracturo the lial carcinoma: a multi institutional study. Urol Oncol 2014;32:19-26.

10. Shariat, SF, Godoy G, Lotan Y, et al. Advanced patientage is associated within ferior cancer-specific survival after radical nephroureterectomy. BJU Int 2010;105:1672.

11. World Health Organization (2015) World Report on Ageingand Health.

12. Yafi FA, Novara G, Shariat SF, et al. Impact of tumour location versus multifocality in patients with upper tract uro the lial carcinomatre ated 
with nephroureterectomy and bladder cuffexcision: a homogeneous series without perioperative chemotherapy. BJU Int 2012;110:7-13.

13. Ouzzane A, Colin P, Xylinas E, et al. Ureteral and multifocaltumours have worse prognosis than renal pelvictumours in urothelialcarcinoma of the upper urinary tract treated by nephroureterectomy. EurUrol 2011;60:1258-1265.

14. Baboudjian M, Lechevallier E, Michel F, et al. Does diagnostic ureter orenoscopy increase the risk of bladder recurrence after total nephroureterectomy? A review of the literature. ProgUrol 2019;29:138-146.

15. Munoz JJ, Ellison LM. Upper Tracturo The Lialneoplasms: Incidence and Survival During The Last 2 Decades. J Urol 2000;164:1523-1525.
16. Chromecki, TF, Cha EK, Fajkovic H, et al. The Impact of Tumormultifocality on Outcomes in Patients Treated with Radical Nephroureterectomy. EurUrol 2012;61:245-253.

17. Raman JD, Ng CK, Scherr DS, et al. (2010) Impact of Tumorlocation on Prognosis for Patients with Upper Tracturo The Lial Carcinoma Managed by Radical Nephroureterectomy. Eururol 57:1072-1079.

18. Fradet V, Mauermann J, Kassouf W, et al. Risk Factors for Bladder Cancer Recurrence After Nephroureterectomy for Upper Tracturo the Lialtumors: Results from the Canadian Upper Tract Collaboration. Urol Oncol 2014;32:839-845. 